\title{
PELATIHAN DAN PENDAMPINGAN BUDIDAYA SAYUR ORGANIK DI DESA BAROS, KABUPATEN SERANG
}

Riki Rikardo

Institut Pertanian Bogor

\author{
Hadi Susilo * \\ Universitas Mathla'ul Anwar \\ Banten
}

\section{Herlina Siti Nurantika}

Universitas Mathla’ul Anwar Banten

\begin{abstract}
TRAINING AND MENTORING OF ORGANIC VEGETABLE CULTIVATION IN BAROS VILLAGE, SERANG REGENCY. The increasing number of people and public awareness about the health of the growing demand for organic vegetables is also increasing. This is one of the business opportunities in the field of organic agriculture, especially organic vegetable cultivation. The economic analysis of organic vegetable cultivation shows that organic vegetable cultivation is profitable, so it can be used as an effort to increase people's income. Organic vegetables are vegetables that are processed by environmentally friendly process, using organic materials from agricultural and livestock waste, without using synthetic chemical fertilizers, and synthetic pesticides. Baros Village, Baros District, Serang District is an agricultural area suitable for organic vegetable cultivation, the availability of land for agriculture, good irrigation, organic fertilizer source widely available, and close to the capital of Banten province. Organic vegetable cultivation uses organic ingredients from agricultural and livestock waste that are around the site. Selection of vegetable seeds is done by selecting seeds that are superior and needed by the community. Soil processing is done by plowing the soil, followed by basic fertilization. Organic vegetable preservation is done with advanced organic fertilization, weeding, irrigation, and vegetable pesticide administration. The harvesting process is done by selecting good organic vegetables, washing, and packing vegetables. The most important aspect of community service programs is the potential for sustainability. The sustainability of the Organic Vegetable Cultivation program is able to support the economy and public health.
\end{abstract}

KEYWORDS: Baros Village, Organic Fertilizer, Organic Vegetables, Vegetable Pesticides.

* Corresponding Author: Program Studi Biologi Fakultas Sains dan Farmasi (FSF) Universitas Mathla'ul Anwar Banten; Jalan Raya Labuan KM. 23 Saketi, Kabupaten Pandeglang, Banten 42273, Indonesia; Email: hadisusilo1973@gmail.com

Article History: Received: 29-06-2017; Revised: 21-11-2017; Accepted: 12-12-2017

Permalink: http://ppm.ejournal.id/index.php/pengabdian/article/view/29

How to cite (APA): Rikardo, R., Susilo, H., \& Nurantika, H. S. (2017). Pelatihan dan pendampingan budidaya sayur organik di desa Baros, kabupaten Serang. Jurnal Pengabdian Pada Masyarakat, 2(2), 159-166.

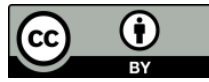

This is an open access article distributed under the terms of the Creative Commons Attribution 4.0 Internationa License, which permits unrestricted use, distribution, and reproduction in any medium, provided the original work is properly cited. @ 2017, Riki Rikardo, Hadi Susilo, Herlina Siti Nurantika.

\section{PENDAHULUAN}

Pertanian organik merupakan salah satu metode produksi pertanian yang ramah lingkungan. Sistem produksi pertanian organik mendasarkan pada standar yang tepat dan spesifik produksi pertanian yang bertujuan mengembangkan 
agroekosistem secara sosial dan ekologis berkelanjutan. Pertanian organik merupakan sistem pertanian yang meminimalkan penggunaan input luar, menghindarkan penggunaan pupuk kimia sintetis, pestisida sintetis (herbisida, fungisida), mikroba hasil rekayasa genetik, bahan aditif, dan pengawet sintetis (Sutanto, 2002).

Salah satu alternatif produksi makanan yang sehat dan alami adalah dengan menggunakan sistem pertanian organik, sebab sistem pertanian organik tidak memakai hormon sintetik, obat-obatan, pestisida, dan pupuk kimia sintetis. Menurut IFOAM (International Federation of Organic Agriculture Movements), tujuan yang hendak dicapai dengan penggunaan sistem pertanian organik antara lain: (1) mendorong dan meningkatkan daur ulang dalam sistem usaha tani dengan mengaktifkan kehidupan jasad renik, flora dan fauna, tanah, tanaman serta hewan, (2) memberikan jaminan yang semakin baik bagi para produsen pertanian (terutama petani) dengan kehidupan yang lebih sesuai dengan hak asasi manusia untuk memenuhi kebutuhan dasar serta memperoleh penghasilan dan kepuasan kerja, termasuk lingkungan kerja yang aman dan sehat, dan (3) memelihara serta meningkatkan kesuburan tanah secara berkelanjutan (IFOAM, 2005)

Sistem pertanian organik berpijak pada kesuburan tanah sebagai kunci keberhasilan produksi dengan memperhatikan kemampuan alami dari tanah, tanaman, dan hewan untuk menghasilkan kualitas yang baik bagi hasil pertanian maupun lingkungan. Ada tiga kunci yang harus ada pada sistem pertanian organik, yaitu: (1) merupakan suatu sistem pertanian menyeluruh; (2) membatasi bahan aatau input nonorganik; dan (3) menjaga kelestariaan dan kelangsungan agroekosistem. Prinsip pertanian organik adalah bersahabat dan selaras dengan lingkungan (Hendras et al, 2013).

Sektor pertanian merupakan sektor yang potensial dikembangkan untuk memulihkan perekonomian dalam rangka otonomi daerah. Sektor pertanian Indonesia terdiri dari tiga sub sektor yaitu sub sektor tanaman perkebunan, tanaman pangan dan tanaman hortikultura. Hortikultura sebagai salah satu sub sektor pertanian terdiri dari berbagai jenis tanaman hias, sayuran, buah-buahan dan tanaman obat-obatan. Produk hortikultura khususnya sayuran dan buah-buahan berperan dalam memenuhi gizi masyarakat terutama vitamin dan mineral yang terkandung di dalamnya. Hal ini juga penting dalam peningkatan kualitas sumber daya manusia sebagai pelaku pembangunan ekonomi. Dalam struktur pembentukan PDB sektor pertanian, subsektor hortikultura menyumbang sebesar 23 persen dan menempati posisi kedua terbesar setelah tanaman pangan. Sementara 
itu dalam PDB sub sektor hortikultura sayuran menempati urutan kedua setelah tanaman buah dan PDB sayuran juga meningkat dengan laju rata-rata 8 persen per tahun dari 2002-2005 (Deptan, 2006).

Permintaan sayuran yang dikonsumsi sebagai bahan pelengkap makanan pokok akan terus berfluktuasi seiring dengan semakin bertambahnya jumlah penduduk. Dari tahun ke tahun, populasi penduduk Indonesia semakin meningkat. Pada tahun 2000, jumlah penduduk Indonesia yaitu sekitar 205 juta jiwa dan pada tahun 2005 jumlah penduduknya sudah mencapai 219 juta jiwa. Sedangkan menurut data statistik Indonesia, jumlah penduduk tahun 2007 yaitu sekitar 224 juta jiwa dan proyeksi jumlah penduduk pada tahun 2010 akan mencapai 233 juta jiwa. Pertambahan jumlah penduduk di Indonesia memperlihatkan peningkatan yang cukup pesat. Hal ini terlihat terutama pada kenaikan setiap lima tahunnya, penduduk Indonesia bertambah kurang lebih sekitar 14 juta jiwa (BPS, 2010).

Dengan terus meningkatnya jumlah penduduk di Indonesia, maka secara langsung dapat mempengaruhi konsumsi sayuran di Indonesia. Konsumsi sayuran per kapita dalam lima tahun terakhir yang paling tinggi adalah pada tahun 2005, yaitu dari keseluruhan macam sayuran sebesar 35,30 kg/tahun. Konsumsi sayuran per kapita di Indonesia menunjukkan perkembangan yang fluktuatif dan meningkat seiring dengan meningkatnya jumlah kelas menengah yang ada (Deptan, 2006).

Perhatian masyarakat yang tinggi pada kesehatan, menjadikan sistem pertanian organik terutama untuk komoditi sayuran organik memiliki peluang yang besar untuk dikembangkan. Oleh karena itu, walaupun dihadapi dengan berbagai macam kendala, banyak produsen-produsen sayuran organik yang bermunculan.

\section{METODE PELAKSANAAN}

Pelaksanaan kegiatan budidaya sayur organik dilakukan melalui pelatihan, pendampingan, dan pencapaian hasil produksi. Adapun tahapan budidaya sebagai berikut:

Pengolahan tanah, dilakukan dengan pembajakan tanah, tanah dibalik strukturnya agar tidak padat.

Pemupukan dasar, dilakukan dengan pemberian pupuk kandang hasil dari peternakan ayam. Tanah yang telah dibajak lapisan bagian atas tanah diberi pupuk kandang, dan dibiarkan selama seminggu.

Pemilihan benih sayur unggul, dilakukan dengan membeli benih sayur unggul yang tersertifikasi oleh Deptan. Pemilihan komoditas sayur dipilih 
berdasarkan komoditas sayur yang banyak dibutuhkan di masyarakat, antara lain: selada, kangkung, dan timun.

Pemupukan lanjut, diberikan setelah benih ditanam selamaa dua minggu setelah masa tanam. Pupuk lanjut yang diberikan adalah pupuk organik yang diperkaya dengan bakteri pemacu pertumbuhan tanaman. Pemberian pupuk dilakukan setiap dua minggu sekali, sampai menjelang sayur organic panen.

Pengendalian hama dan penyakit, dilakukan dengan penyemprotan pestisida nabati, tiga hari setelah dilakukan pemupukan sayur organik.

Pemeliharaan sayur organik, dilakukan dengan menyiangi gulma yang terdapat pada tanaman sayur organik, penjarangan tanam sayur organik, penyemprotan pestisida nabati untuk mencegah hama dan penyakit.

Pemanenan, sayur organik dipilih, disortir sesuai dengan ukuran sayur organik yang sama, kemudian dilakukan pencucian dengan menggunakan air bersih.

Pengemasan sayur organik, dilakukan baik sesuai pesanan konsumen atau sayur dikemas dalam plastik bening per $20 \mathrm{~kg}$. sayuran yang telah dikemas yang sudah siap jual bias diambil oleh pedagang, atau bias langsung di kirim ke pasar (Hendras dkk, 2013: BPPP, 2015)

Berdasarkan tahapan di atas, maka dapat digambarkan teknologi yang diterapkan pada bagan yang disajikan pada Gambar 1 .

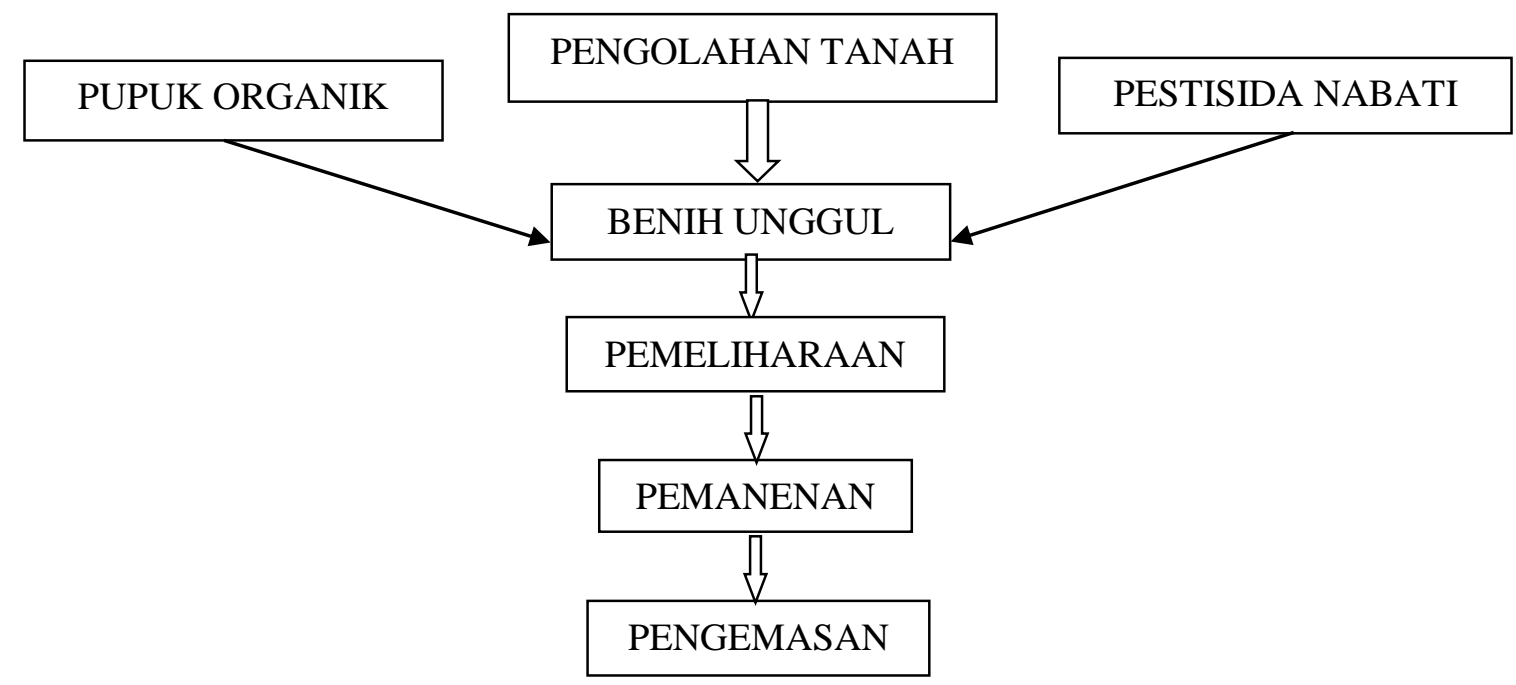

Gambar 1. Teknologi yang Diterapkan 


\section{HASIL DAN PEMBAHASAN}

Desa Baros merupakan salah satu desa yang terletak di Kecamatan Baros, Kabupaten Serang Banten. Desa Baros merupakan desa yang wilayahnya sebagian besar digunakan untuk pertanian dan peternakan ayam. Masyarakat di Desa Baros sebagian besar adalah petani, buruh tani, bekerja di sektor industri dan perdagangan.

Di sektor pertanian, masyarakat Desa Baros sebagain besar menanan padi. Petani di Desa Baros rata-rata memiliki lahan atau sawah seluas $2000 \mathrm{~m}^{2}$, sedangkan buruh tani mengerjakan sawah dengan sistem bagi hasil atau menyewa kepada petani yang mempunyai lahan sawah. Saluran irigasi memang belum tersedia dengan baik, beberapa bagian wilayah desa masih menggunakan sumur pompa untuk mengairi sawah. Panen padi dapat dilakukan 2 kali dalam satu tahun, disela-sela panen padi masyarakat memanfaatkan sawahnya dengan menanam sayuran. Sayuran yang biasa ditanam antara lain: timun, kangkung, cabe dan tomat.

Budidaya sayuran masih dilakukan secara konvensional, belum dikelola secara baik atau hanya sekedar mengisi waktu sela sebelum penanaman padi. Petani di desa Baros rata-rata sudah berumur diatas 50 tahunan, sehingga dari sisi produktivitas petani di Desa Baros mulai menurun produktivitasnya. Pemudapemuda di Desa Baros banyak yang tidak berminat lagi menjadi petani, hal ini terlihat setelah mereka lulus sekolah mencari pekerjaan di kota sekitarnya, seperti di Tangerang dan Jakarta. Pertanian menjadi pekerjaan tidak menarik lagi, tentu ini harus menjadi perhatian semua pihak.

Pengelolaan budidaya sayuran organik yang benar menjadi salah satu solusi daya tarik masyarakat terhadap sektor pertanian. Budidaya sayur organik adalah budidaya sayur dengan memanfaatkan potensi sumberdaya lokal hasil limbah pertanian dan peternakan, tanpa menggunakan pupuk kimia dan pestisida sintetis, untuk menghasilkan sayur organik yang sehat dan berkualitas. Budidaya sayur organik juga dapat memperbaiki struktur tanah yang rusak akibat pemakaian pupuk kimia berlebih, mengurasi residu pemakaian pestisida, dan dapat menjaga kelestarian lingkungan. Budidaya sayur organik diharapkan dapat meningkatkan pendapatan petani di Desa Baros, dengan meningkatnya pendapatan petani kesempatan untuk memberikan pendidikan kepada anaknya akan semakin meningkat, kesejahteraan petani juga dapat meningkat.

Pemilihan komoditas yang akan dibudidayakan secara organik tergantung pada risiko produksi dan permintaan konsumen. Pola tanam sayuran organik meliputi monokultur dan tumpang sari. Pola monokultur adalah pada satu 
hamparan terdapat satu jenis komoditas sayuran, sedangkan pola tumpang sari terdiri atas beberapa jenis komoditas sayuran dalam suatu hamparan tertentu. Pola tanam tumpangsari bertujuan agar penggunaan tiap bedengan lahan lebih efektif, untuk memutuskan siklus hama dan menghindari terjadinya kompetensi hara. Pola tanam secara tumpangsari disarankan memenuhi beberapa syarat yaitu jenis sayuran buah ditumpangsarikan dengan sayuran berdaun, sayuran umbiumbian ditumpangsarikan dengan sayuran berdaun, tanaman sayuran berakar serabut ditumpangsarikan dengan tanaman sayuran berakar tunggal, tanaman sayuran yang berumur panjang (satu musim/tiga bulan) ditumpangsarikan dengan tanaman sayuran berumur pendek (tiga minggu), dan tanaman yang tahan naungan ditumpangsarikan dengan tanaman yang lebih tinggi (BPPP, 2015)

Petani Desa Baros menggunakan pola tumpang sari dengan timun sebagai tanaman utama dan selada sebagai tanaman sela. Pemilihan ini berdasarkan pangsa pasar yang dimungkinkan lebih menguntungkan. Penelitian Tarigan (2009) menunjukkan bahwa berdasarkan analisis risiko produksi pada bayam hijau, brokoli, tomat dan cabai keriting, risiko produksi bayam hijau lebih tinggi dibandingkan dengan brokoli, tomat dan cabai keriting; sedangkan risiko paling rendah adalah cabai keriting. Hal ini dikarena bayam hijau sangat rentan terhadap penyakit terutama pada musim hujan. Berdasarkan pendapatan bersih, risiko yang paling tinggi dari keempat komoditas adalah cabai keriting, sedangkan yang paling rendah adalah brokoli. Hal ini disebabkan penerimaan yang diterima lebih kecil sedangkan biaya yang dikeluarkan tinggi. Kegiatan diversifikasi tanaman dapat menurunkan risiko.

Kelebihan dari pertanian organik antara lain sebagai berikut: tidak menggunakan pupuk maupun pestisida kimia sehingga tidak menimbulkan pencemaran lingkungan, produksi yang dihasilkan pertanian organik lebih nyaman dikonsumsi dibanding produksi yang dihasilkan pertanian non organik dan harga produksi dari pertanian organik lebih mahal dibanding dengan non organik (Hendras et al, 2013).

Peningkatan dalam usaha pertanian dilakukan pemupukan dengan bahan alami. Bahan-bahan alami yang telah mengalami pelapukan dapat dijadikan pupuk. Bahan-bahan alami memiliki sifat dapat memperbaiki sifat-sifat tanah, dapat mempertahankan kelembaban tanah,dapat menjadi sumber zat-zat makanan bagi tumbuh-tumbuhan dan dapat menjadi sumber makanan bagi pertumbuhan mikroorganisme di dalam tanah. Pemupukan tanaman diberikan untuk memberi makanan (nutrisi) pada tanaman. Dalam melakukan pemupukan untuk pertanian 
alami, tidak terjadwal seperti pertanian konvensional, tetapi sesuai kebutuhan tanaman. Dalam pertanian alami, perlu diperhatikan, jika tanaman kekurangan salah satu unsur yang menjadi makanan utama (BPPP, 2013).

Tanaman sayuran lebih cepat panennya dibanding tanaman semusim lainnya dan juga tanaman sayuran tergantung varietas yang ditanam cara panen sayuran tergantung jenis sayurannya yaitu ada yang dicabut, dipetik dan dipotong. Pasca panen merupakan kegiatan akhir pada proses produksi, dimana pada tahap pasca panen ini sayur-sayuran yang sudah dipanen diperlakukan sebagaimana mestinya. Kegiatan pasca panen yang dilakukan, pertama penerimaan barang, barang yang dibawa dari lapangan ada yang ditimbang langsung, kemudian dilakukan pencatatan, tetapi ada yang dicuci, sortir, baru ditimbang. Setiap barang yang masuk akan ditimbang dan dilakukan pencatatan. Kedua penggradingan dan sortir atau pemilahan sayur dilakukan melalui proses. Sayuran perlu dilakukan perompelan ulang selain itu juga penggradingan sayuran berdasarkan kriteria pelanggan, dapur atau kompos. Ketiga pembuatan bon dan terakhir pengiriman sayur ke pelanggan (Hendras et al, 2015).

Selain hama, sistem irigasi dan iklim menjadi kendala dalam budidaya sayura organik. Sistem irigasi di lahan kering pada umumnya hanya mengandalkan dari air hujan, padahal akhir-akhir ini keadaan iklim sulit untuk diprediksi, kadangkadang curah hujan terjadi sangat tinggi yang menyebabkan kerusakan fisiologis tanaman dan menimbulkan tingginya serangan hama dan penyakit tanaman, tetapi sewaktu-waktu terjadi musim kemarau cukup ekstrim yang dapat mengakibatkan tanaman kekurangan air, akhirnya pertumbuhan tanaman menjadi kurang baik bahkan sebagian banyak yang mati dan pada akhirnya petani banyak yang mengalami kerugian karena gagal panen (Syukur \& Maya, 2015).

Petani di Desa Baros mendapatkan wawasan baru, pemahaman dan ketrampilan teknik tentang budidaya sayur organik. Program budidaya sayur organik yang bertujuan untuk menghasilkan sayur organik serta menambah penghasilan masyarakat petani sayur di Desa Baros Kecamatan Baros Kabupaten Serang. Keuntungan diperoleh dari menanam sayur organik. Lahan seluas $2500 \mathrm{~m} 2$ dengan penanaman sebanyak 6000 pohon. Setiap pohon menghasilkan 2 kilogram timun segar dengan harga $\mathrm{Rp} 1.500,-$ mendapatkan hasil Rp 18.000.000,- dalam setiap masa panen.

Peranan pemerintah, akademisi dan praktisi diperlukan dalam rangka meningkatkan kualitas sumberdaya petani, sehingga petani lebih kreatif, inovatif, mandiri dan berdaya saing. Keberlanjutan program Budidaya Sayur Organik 
mampu mendukung ekonomi masyarakat, ketika masyarakat mampu menghasilkan sayur organik, maka hal tersebut dapat meningkatkan taraf hidup masyarakat secara ekonomi. Budidaya Sayur Organik juga menghasilkan sayur yang bebas pestisida kimia sehingga masyarakat yang mengkonsumsinya secara tidak langsung mengurangi asupan zat kimia pada sayuran yang biasanya dikelola dengan menggunakan pestisida kimia.

\section{SIMPULAN}

Budidaya sayur organik di Desa Baros Kecamatan Baros Kabupaten Serang mampu memberikan dampak positif yang cukup signifikan kepada petani, salah satunya adalah softskill melalui pelatihan ketrampilan dan pencapaian hasil produksi sayur organik. Keberlanjutan program Budidaya Sayur Organik mampu mendukung ekonomi dan kesehatan masyarakat, sehingga kesejahteraan masyarakat dengan sendirinya akan tercapai.

\section{REFERENSI}

BPPP. (2015). Inovasi hortikultura pengungkit peningkatan pendapatan rakyat. Bogor: Badan Penelitian dan Pengembangan Pertanian, Pusat Perpustakaan dan Penyebaran Teknologi Pertanian.

BPS. (2010). Sensus penduduk Indonesia. Jakarta: Badan Pusat Statistik.

Deptan. (2006). Tanaman sayuran. Jakarta: Departemen Pertanian.

Hendras, E. W., Haerudin, R. S., Bambang, R, S., Nano, S., Jueni, Edi H., Bambang L., Ayu A.J., Bonaji, Erwindo, Suhadi dan Sutarto. (2013). Pertanian alami; Budidaya sayuran alami. Bogor: Konsorsium YABI-WCS-YAPEKA.

IFOAM. (2005). The IFOAM norms for organic production and processing including IFOAM basic standards and IFOAM accreditation criteria. Version 2005. Bonn, Germany: IFOAM.

Syukur, M., \& Maya, M. (2015). Pengembangan Sayur Organik. Bogor: IPB Press.

Tarigan, P. E. S. B. (2009). Analisis risiko produksi sayuran organik pada permata hati organik farm di Bogor Jawa Barat. (Unpublished undergraduate's thesis) Institut Pertanian Bogor, Indonesia. 